\title{
SELECTIVE THREE-PHASE CURRENT REFERENCE GENERATION USING MULTI-RESONANT METHOD FOR SHUNT ACTIVE POWER FILTER
}

\author{
Cássio X. Rocha ${ }^{1,2}$, José R. Camacho ${ }^{1}$, Ernane A. A. Coelho ${ }^{1}$, Wanderley A. Parreira ${ }^{3}$ \\ ${ }^{1}$ Universidade Federal de Uberlândia, Uberlandia - MG, Brasil \\ ${ }^{2}$ Instituto Federal de Goiás, Itumbiara - GO, Brasil \\ ${ }^{3}$ Centro Federal de Educação Tecnológica de Minas Gerais, Araxá - MG, Brasil \\ e-mail: cassio.rocha@ifg.edu.br, jrcamacho@ufu.br, ernane@ufu.br, waparreira@ des.cefetmg.br
}

\begin{abstract}
This paper proposes the application of an accurate, fast and stable method to be used by the control systems in the selective compensation of harmonic currents in three phase systems susceptible to frequency changes and phase jumps. This application is based on a MSOGI-FLL (Multiple Second Order Generalized Integrators - Frequency Locked Loop) method, which is composed of multiple double adaptive filters called Dual Second Order Generalized Integrators (DSOGI) coupled to the frequency detector entitled Frequency Locked Loop (FLL) which keeps the set synchronized, even in abnormal situations.
\end{abstract}

Keywords - Frequency-Locked-Loop (FLL), MSOGI, Selective Harmonic Compensation (SHC), Shunt Active Power Filter.

\section{INTRODUCTION}

Due to the increasing use of residential electronic loads and industrial equipment evermore based on semiconductor composed inherent devices, such as soft-starters and voltage inverters, the production of large current harmonic distortions in transmission and distribution networks becomes inevitable [1]. In the past, different solutions were used in order to minimize the effects of harmonic distortion, the main one being passive filters. However, with the great technological development of switching devices, microcontrollers and digital control systems, Active Power Filters (APF) gained importance. These were the brainchild of laboratories, which were transformed into real electrical systems and are currently in use. However, given the great complexity of transmission and distribution systems, along with the expansion of independent distributed generation systems connected to the electrical network, the APF control systems need to continue supply under a variety of different situations, such as high harmonic currents, variations in frequency and even phase jumps in the power system.

Due to the importance of APF in electric current quality in transmission and distribution systems, the scientific community has researched different configurations and control methodologies of such filters. The implemented active filters without harmonic extractors [2], flexible harmonic compensation [3], compensation based on the conservative power theory [4], compensation algorithms based on the PQ

Manuscript received 11/04/2016; first revision 19/06/2016; accepted for publication 05/08/2016, by recommendation of Editor Marcelo Cabral Cavalcanti. and $\mathrm{CPC}$ theories [5], current compensation with photovoltaic generation [6] and characterization and compensation of harmonic and reactive [7] are some of the works developed.

Active filters with selective compensation of harmonics has some advantages compared to total compensation of harmonics, such as the drastically reduced bandwidth and the lower possibility of occurrence of dangerous oscillations between the filter and the load due to the presence of capacitive or resonant components on the load [8], [9], [10]. In medium/high-power systems where the switching frequency of the active power filter is low to avoid power loss, the selective harmonic compensation become especially important, since traditional high frequency active filters cannot be used [11].

By using such active filters in conjunction with conventional passive filters, very interesting results can be observed. The active filter suppress some harmonics near the fundamental frequency, and the higher harmonics can be mitigated easily using the passive filters or reduced by the line impedance of a power system [12]. For the sake of the research in this field, this work shows that an APF can be split into various control modules, as seen in Figure 1, such as 1) Generation of harmonic reference currents for compensation. 2) PWM control for the voltage inverter in order to generate the inverse of the harmonic currents for compensation. 3) Algorithm for the detection of failures and islanding.

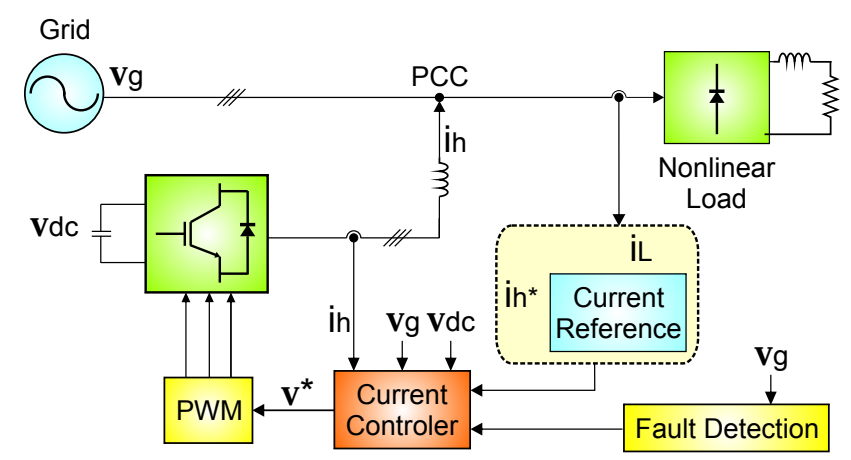

Fig. 1. Simplified harmonic compensation circuit. The dotted section is the part under study in this paper.

Harmonic detection methods are crucial to the APF, the speed and accuracy of the method used are crucial to the implementation of stable control strategies under harsh conditions. The existing disturbances encountered on the power grid can lead to compensation of harmonic currents that do not exist on the network, or are lagged, compromising the operation of the whole project. There are a number of 
methods, different topologies and algorithms for the detection of harmonics. These methods can be implemented in the frequency domain or the time domain. In the frequency domain, these methods take on the Discrete Fourier Transform (DFT) [13], the Fast Fourier Transform (FFT) [14] and the Recursive Discrete Fourier Transform (RDFT) [15]. The main disadvantage of the methods that use Fourier Transforms and their variants is the need of high processing speed and large memory microcontrollers for storing signal samples during a complete cycle of the main frequency. In addition to this, these methods give inaccurate results in unstable conditions [16]. The methods in the time domain use simple calculations when compared with the methods in the frequency domain. Among such on notes, Synchronous Reference Frame (SRF) methods and their variants, where it is necessary to use synchronizing angular position mechanism, which may be of complex construction, when considering three-phase unbalanced current with harmonics, oscillating frequency and phase jumps. Another problem is the application of numeric filters, and not being ideal, present errors in amplitude and mainly in phase, causing the harmonic signal detected not to represent the existing harmonic signal on the network [17]. Methods based on the calculation of instantaneous power can only be used in cases of balanced three phase currents [18] furthermore they also have the need to use digital filters, presenting the same amplitude and phase errors described in synchronous methods. The generalized integrators (GI) overcome the limitations of PI (proportional integral) controllers in $d q$ frame of reference that do not have good traceability of signals with harmonics [19]. The GIs are derived from an integration in the time domain, represented by a Laplace second order transfer function, having as an answer an infinite gain at the resonant frequency. The difficulty of this method is that integration constant $(K i)$ of each transfer function (one for each harmonic frequency) should be defined from a pre-existing plant [19]. Improved methods using GI were presented in order to leave the model independent of a specific plant [20]. However, reverted to the use of methods that have proven to be inefficient, such as digital filters that change the amplitude and phase of the signals, and have a need for synchronism of the supply voltage with a PLL, which proved inefficient when there are phase imbalances, frequency variation and jumps in voltage phase on the grid. In this article, the contribution of the authors is present a multi-resonant structure to generate reference signals for selective compensation of the three-phase harmonic currents, implemented using the Multiple Second Order Generalized Integrators (MSOGI-FLL) [21], [22], which until this moment have used only as inverter synchronization method when connected to the power grid.

The harmonic components with more distant frequencies of the fundamental can be mitigated easily using passive filters. The third harmonic component and its multiple can be easily minimized by the use of transformers with D-Y cores. The 5th and 7 th harmonics were chosen in simulation/experiments to be more difficult to be attenuated by passive components.

The contribution of this paper is the presentation of a new application for the MSOGI-FLL method to generate reference currents for selective compensation of harmonic components close to the fundamental frequency in power active filters. MSOGI-FLL was described in [21]-[23], and its application was constituted by a synchronizing voltage converter with the power grid, as proposed by [22], [24].

\section{DECOMPOSITION INTO SYMMETRICAL COMPONENTS OF UNBALANCED THREE-PHASE SYSTEMS}

According to the method of Lyon [25], unbalanced threephase systems can be decomposed into three wave forms lagged at $120^{\circ}$ from each other, called positive sequence symmetrical components rotating anticlockwise, the negative sequence rotating clockwise and zero sequence, with nonrotating components in phase with each other. The positive component is the voltage or current element under balanced nominal conditions, with a positive rotation direction through convention. The negative component is the element voltage or current with the reverse rotation direction. The component is zero voltage or current element with the same fixed phase angle for each phase, and in three-phase three-wire systems, it can be disregarded. This approach not only offers an elegant and standardized method for the analysis of unbalanced polyphase systems, but also allows for a mathematical and physical explanation of existing phenomena in commercial electrical systems currently in operation.

To minimize the computational effort, rather than calculate the positive and negative-phase components of the phases $a$, $b$ and $c$ individually their symmetrical components $\alpha$ and $\beta$ are calculated. Applying $\left[T_{\alpha \beta}\right]$ and $\left[T_{+-0}\right]$, the method arrives at (1) and (2). It can replace $e^{\frac{-i \pi}{2}}$ by $\mathbf{q}$, where the $\mathbf{q}$ operator signifies is a 90 -degree displacement in the input signal.

$$
\begin{aligned}
& i_{\alpha \beta}^{+}=\left[\begin{array}{cc}
1 & -e^{\frac{-i \pi}{2}} \\
e^{\frac{-i \pi}{2}} & 1
\end{array}\right] i_{\alpha \beta}=\frac{1}{2}\left[\begin{array}{cc}
1 & -q \\
q & 1
\end{array}\right] i_{\alpha \beta} \\
& i_{\alpha \beta}^{-}=\left[\begin{array}{cc}
1 & e^{\frac{-i \pi}{2}} \\
-e^{\frac{-i \pi}{2}} & 1
\end{array}\right] i_{\alpha \beta}=\frac{1}{2}\left[\begin{array}{cc}
1 & q \\
-q & 1
\end{array}\right] i_{\alpha \beta}
\end{aligned}
$$

As shown in Figure 2, it is possible to calculate the positive symmetrical components $\left(i_{\alpha}^{+}\right.$and $\left.i_{\beta}^{+}\right)$and negative $\left(i_{\alpha}^{-}\right.$and $\left.i_{\beta}^{-}\right)$ of the input signal $i$ from (1) and (2) [26]. As can be seen both in the block diagram of Figure 2, as in (1) and (2) for calculating the $i_{\alpha}^{+}, i_{\beta}^{+}, i_{\alpha}^{-}$and $i_{\beta}^{-}$the quadrature signal is needed from $i_{\alpha \beta}\left(q i_{\alpha \beta}\right)$.

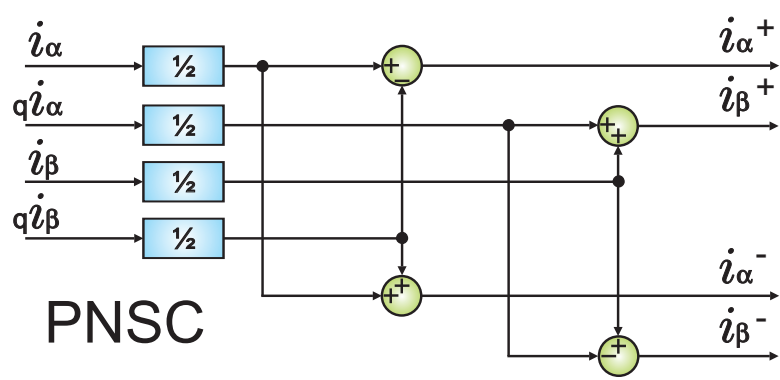

Fig. 2. Positive/Negative Sequence Calculation block. 


\section{GENERATING QUADRATURE SIGNALS}

A Second Order Generalized Integrator (SOGI), shown in Figure 3, is an adaptive filter [26]-[29], which provides signals in quadrature, i.e., provides a filtered signal at the same amplitude as the input signal and another signal which is identical to the first but 90 degrees out of phase. The two output signals in quadrature of SOGI quadrature are represented by transfers function (3) and (4) where $\omega^{\prime}$ is the signal frequency to be filtered, $k$ represents the filter damping factor, and $i^{\prime}$ and $q i^{\prime}$ are filtered outputs in-phase and quadrature respectively of the input signal $i$. One can see that this diagram uses only simple arithmetic operations such as addition, subtraction and multiplication (do not use trigonometric function) [22], [24], and can be easily implemented onto microcontrollers.

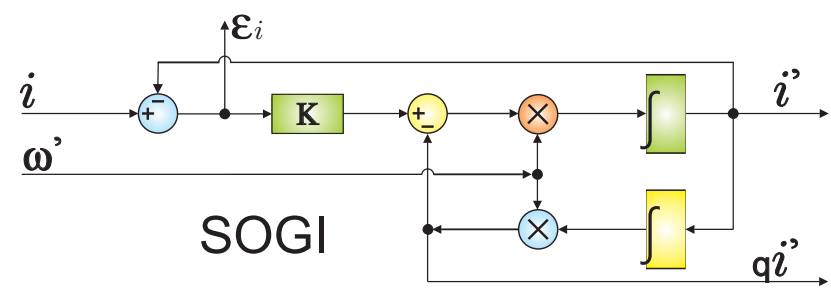

Fig. 3. Second Order Generalized Integrators.

$$
\begin{aligned}
& D(s)=\frac{i^{\prime}}{i}(s)=\frac{k \omega^{\prime} s}{s^{2}+k \omega^{\prime} s+\omega^{\prime 2}} \\
& Q(s)=\frac{q i^{\prime}}{i}(s)=\frac{k w^{\prime 2}}{s^{2}+k \omega^{\prime} s+\omega^{\prime 2}}
\end{aligned}
$$

From transfers function (3) and (4), and considering an input signal as a sinusoidal signal of frequency $\omega$ constant $(i=I \sin (\omega t+\phi))$, the SOGI response time shown in Figure 3 is written as in (5) and (6), where $k<2$.

$$
\begin{aligned}
& i^{\prime}=I \cdot \sin (\omega t)-\frac{I}{\sqrt{1-k^{2} / 4}} \sin \left(\sqrt{\frac{1-k^{2}}{4} w t}\right) e^{-\frac{k \omega}{2} t} \\
& q i^{\prime}=-I \cdot \cos (\omega t)-\frac{I}{\sqrt{1-k^{2} / 4}} \cos \left(\sqrt{\frac{1-k^{2}}{4} w t}\right) e^{-\frac{k \omega}{2} t}
\end{aligned}
$$

As proposed in [30], the settling time of a second-order system can be estimated by $t_{s}=4.6 \tau$. In (5) and (6), one has $\tau=\frac{2}{k \omega^{\prime}}$, thus the SOGI settling time can be approximated by:

$$
t_{s}(S O G I)=\frac{9.2}{k \omega^{\prime}} .
$$

From (7), the conclusion is reached that the higher the $k$ value, the faster the SOGI settling in time. However, the gain $k$ also affects the bandwidth of SOGI where a very high value of $k$ reduces the immunity of SOGI regarding the harmonic components of the input signal, but on the other hand, too low a $k$ gives rise to a very long transient response of an undamped SOGI. The Bode diagram for values of $k=0.1,1.0$ and 2.0 is shown in Figure 4.

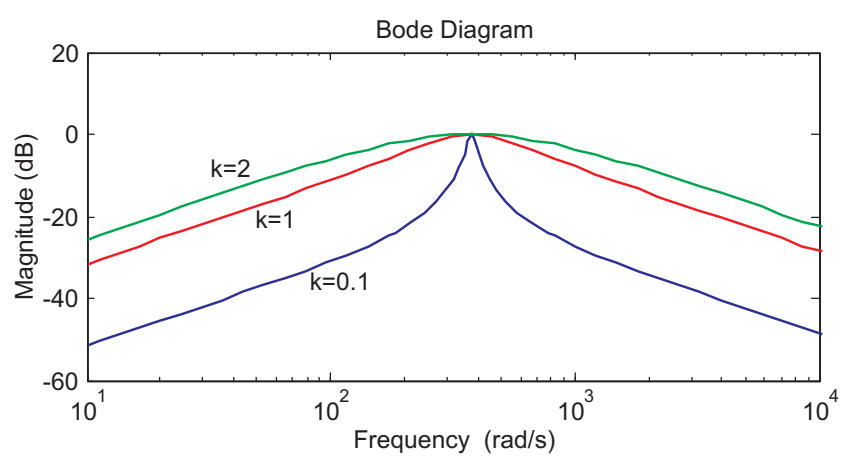

Fig. 4. Bode diagram of the SOGI transfer function (3) with different values of $\mathrm{k}$.

Figure 5 shows $\varepsilon_{i}$ in SOGI considering different values of $k$. In all cases, the amplitude of the sinusoidal input signal falls for under $20 \%$ of its nominal value while the frequency is kept constant at $60 \mathrm{~Hz}$. Figure 5(a) shows the input signal $i$, and Figures 5(b), 5(c) and 5(d) show errors $\varepsilon_{i}$ of SOGI for $k$ values equal to $0.5, \sqrt{2}$ and 2 respectively.

It can be concluded from Figure 5, the best situation between dynamic range and oscillations can be achieved with $k=\sqrt{2}$. The settling time SOGI can be obtained from (7), that is $T_{s(\text { sogi })}=17.5 \mathrm{~ms}$.

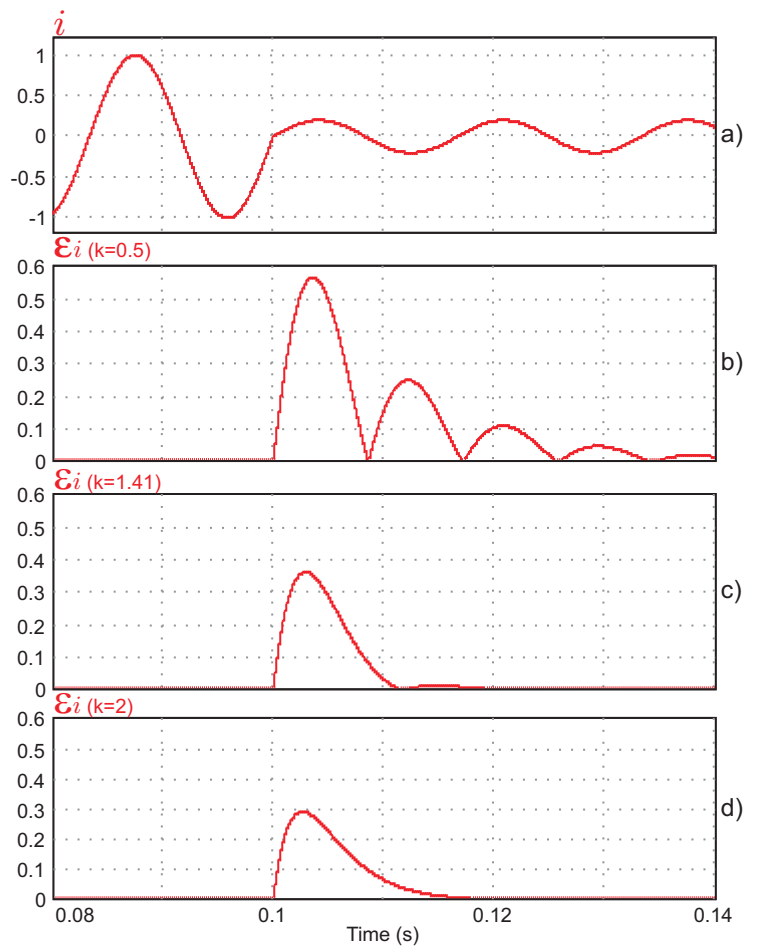

Fig. 5. (a) Input signal with a drop of $80 \%$ of the initial value. (b) Stabilization of $\varepsilon_{v}$ for $k=0.5$. (c) Stabilization of $\varepsilon_{v}$ for $k=\sqrt{2}$. (d) Stabilization of $\varepsilon_{v}$ for $k=2$.

\section{TUNING CURRENT IN THE FUNDAMENTAL FREQUENCY}

A structure called SOGI-FLL is presented in [24], where a SOGI is coupled to a tuner module called a Frequency Locked Loop (FLL). There is a mutual feedback between two structures, allowing the SOGI tuning error to act upon the FLL to make the correction of frequency signal, which in turn feeds 
the SOGI at the new corrected frequency. The structure of SOGI-FLL blocks can be seen in Figure 6.

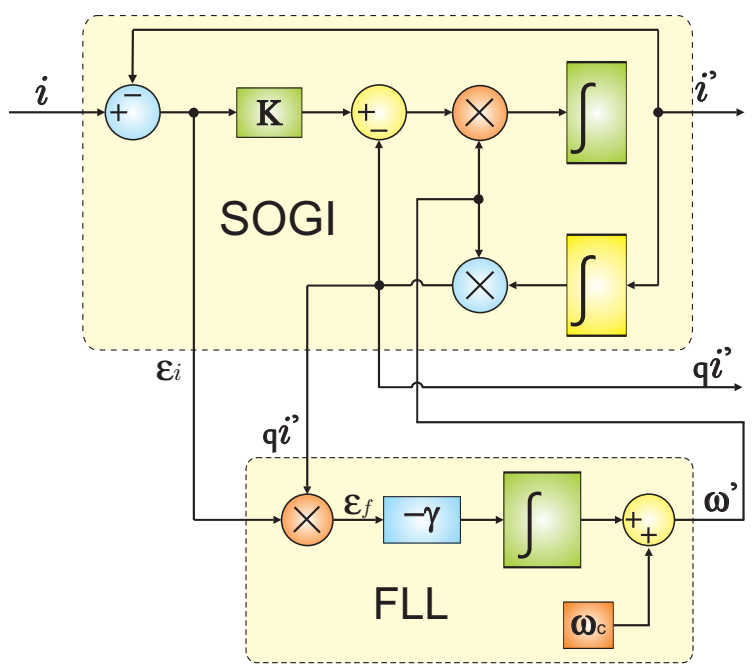

Fig. 6. Second-Order Generalized Integrators FLL (SOGI-FLL).

Considering that the transfer function between the error $\varepsilon_{i}$ and the input signal $i$ is given by $E(s)$ as written (8), and plotting the diagram Bode $E(s)$ and $Q(s)$ as written (4) together, as shown in Figure 7, one notes that the seen that the signals $q i^{\prime}$ and $\varepsilon_{i}$ are in phase when the input frequency is lower than the resonance frequency of the SOGI $\left(\omega<\omega^{\prime}\right)$ and they are in opposite phases when $\omega>\omega^{\prime}$.

$$
E(s)=\frac{\varepsilon_{i}}{i}(s)=\frac{s^{2}+\omega^{\prime 2}}{s^{2}+k \omega^{\prime} s+\omega^{\prime 2}}
$$

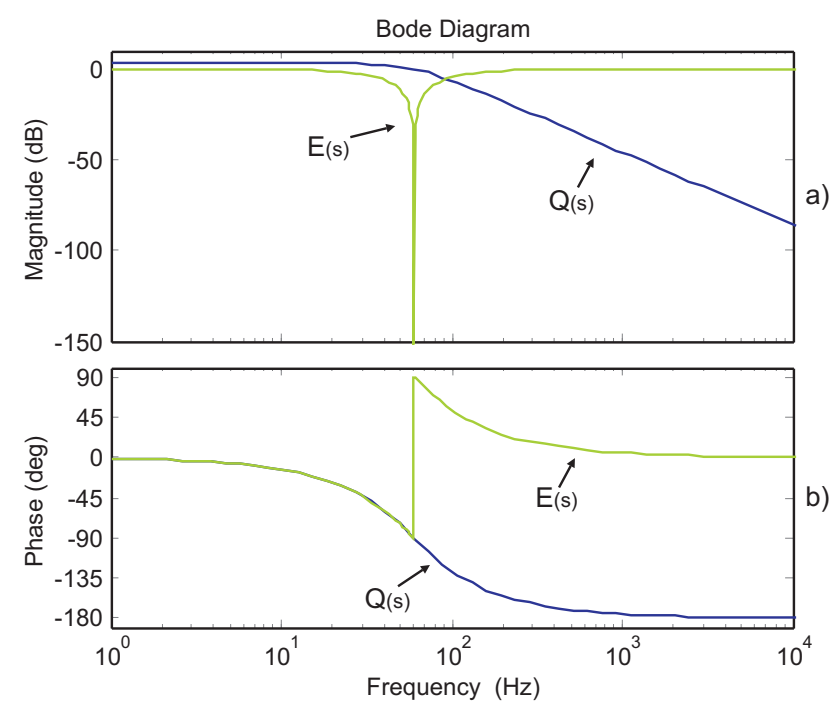

Fig. 7. FLL Bode diagram. (a) Gain. (b) Phase.

If the error of a frequency tuning is defined by the product of $q i^{\prime}$ for $\varepsilon_{i}$, the average value of $\varepsilon_{f}$ will be positive when $\omega<\omega^{\prime}$, zero when $\omega=\omega^{\prime}$, and negative when $\omega<\omega^{\prime}$, as shown in Figure 7. Thus, as illustrated in Figure 6, an integrator controller with a gain $-\gamma$ can be used to cancel a DC component of $\varepsilon_{f}$, changing the resonance frequency $\omega^{\prime}$ of SOGI to the input frequency $\omega$ [23]. As shown in Figure 6, the rated frequency is added at the output of the FLL with a feedback variable $\omega_{c}$ to accelerate the initial synchronization process. According to [21], [22], FLL stabilization time can be approximated by

$$
t_{s(F L L)} \approx \frac{5}{\Gamma} \quad \text { for } \quad \Gamma=\frac{\gamma I^{2}}{k \omega^{\prime}} \quad \text { and } \quad I=\sqrt{i_{\alpha}^{2}+i_{\beta}^{2}} .
$$

The performance and dynamic response of DSOGI-FLL depends on the individual performance of each structure, it can therefore be said that the proper selection of control parameters $k$ and $\gamma$ are of fundamental importance for an appropriate SOGI-FLL response. For both subsystems to have sufficient time to react, FLL dynamics needs to be slower than DSOGI at least two times. In other words, the settle times for the SOGI and the FLL had to be in range of $t_{s(F L L)} \geq 2 . t_{s(S O G I)}$ to ensure enough different constant time in both subsystems to be able to apply (7) and (9) satisfactory to calculate settling times [31].

\section{TUNING THREE-PHASE CURRENTS IN THE FUNDAMENTAL FREQUENCY}

The Double SOGI proposed in [22], [24], and shown in Figure 8 is a composite of two SOGIs and one FFL. The SOGIs filter the signals $i_{\alpha}$ and $i_{\beta}$, and generate the quadrature signals $q i_{\alpha}$ and $q i_{\beta}$ to calculate a symmetrical transformed positive and negative. FLL uses the signals of $S O G I_{\alpha}$ and $S O G I_{\beta}$ to calculate of its fundamental frequency, that feed the two SOGIs. As shown in diagrams of Figure $8, q i_{\alpha}, q i_{\beta}$, $\varepsilon_{i \alpha}$ and $\varepsilon_{i \beta}$ are used to tune FLL in a correct fundamental frequency.

\section{GENERATION OF HARMONIC CURRENT REFERENCES}

The structure MSOGI-FLL proposed in [21] is basically made up of several Dual Second Order Generalized Integrators (DSOGI) in parallel, and an FLL synchronizing module [22]. Each DSOGI represents a channel, and is tuned to the frequency at which one desires to extract the reference current. Figure 9 shows the arrangement of the mentioned components.

The first channel is tuned to the fundamental frequency of the input signal. The fundamental frequency of this signal is used in the calculation of the remaining frequencies (harmonics) for tuning other channels in parallel. The FLL module coupled to the first channel will keep the algorithm synchronized in the fundamental frequency and consequently its harmonics, even in conditions of unbalanced and distorted current, with frequency oscillations and phase jumps.

In order to increase the selectivity of the filter a crossfeedback system between the channels was implemented, called 'Harmonic Decoupling Network' (HDN) [22]. After the transitional period, the filtered output signal from one channel is subtracted from the input signal of the other filter channel, causing the new input signal to have its disturbance attenuated, as shown in Figure 10.

With the use of HDN, the filter transfer function of a channel is given by (10) to $n$ channels where $D_{j}$ is the customized version of the transfer function (3) to $k_{j}=\frac{k}{j}$ and 


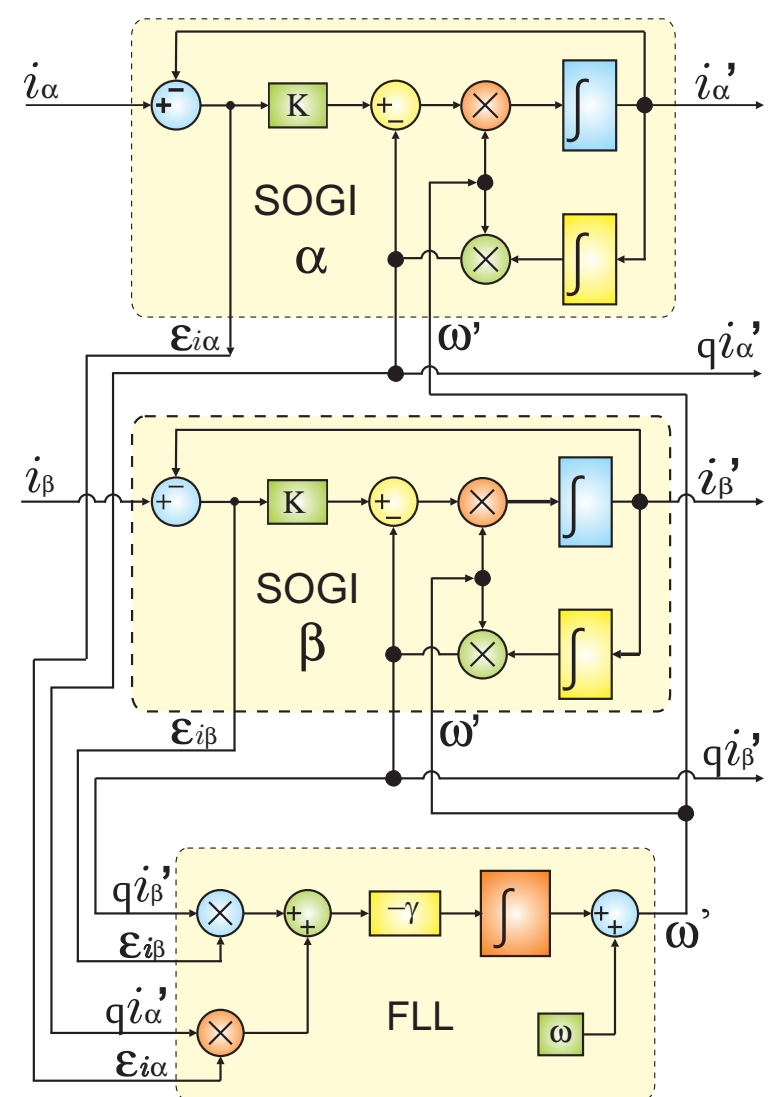

Fig. 8. Double Second-Order Generalized Integrators FLL (DSOGIFLL).

$\omega_{j}=j * \omega$, and $\omega$ the fundamental frequency detected by the FLL.

$$
i_{j}^{\prime}=D_{j}(s)\left(i-\sum_{\substack{l=1 \\ l \neq j}}^{n} i_{l}^{\prime}\right)
$$

Developing the equation system, and substituting $i_{l}^{\prime}$ in (10) by its respective transfer function, one arrives at:

$$
i_{j}^{\prime}=\left[D_{j}(s) \prod_{\substack{l=1 \\ l \neq j}}^{n}\left(\frac{1-D_{l}(s)}{1-D_{j}(s) D_{l}(s)}\right)\right] i .
$$

Bode diagrams of the transfer function (11) for selected frequencies are shown in Figure 11.

According to Fortescue [32], considering that the sequence of phases $(a, b, c)$ at the fundamental frequency of the signal is $0^{\circ},-120^{\circ},+120^{\circ}$, and that the harmonics of order $6 . n+1$ $(7,13,19, \ldots)$ follow the same sequence, it is said that these harmonics are of positive sequence. As for the harmonic orders $6 . n-1(5,11,17, \ldots)$ have the opposite sequence and are considered harmonic of negative sequence. These signals are provided as input to a positive/negative sequence calculation block (PNSC) as shown in Figure 9, which computes the sequence componentes on the $\alpha \beta$ reference frame. Later the filtered harmonic component can be transformed from the stationary system $i_{\alpha \beta}$ to $i_{a b c}$. The PNSC block can be added or removed when a new harmonic component need to be detected.

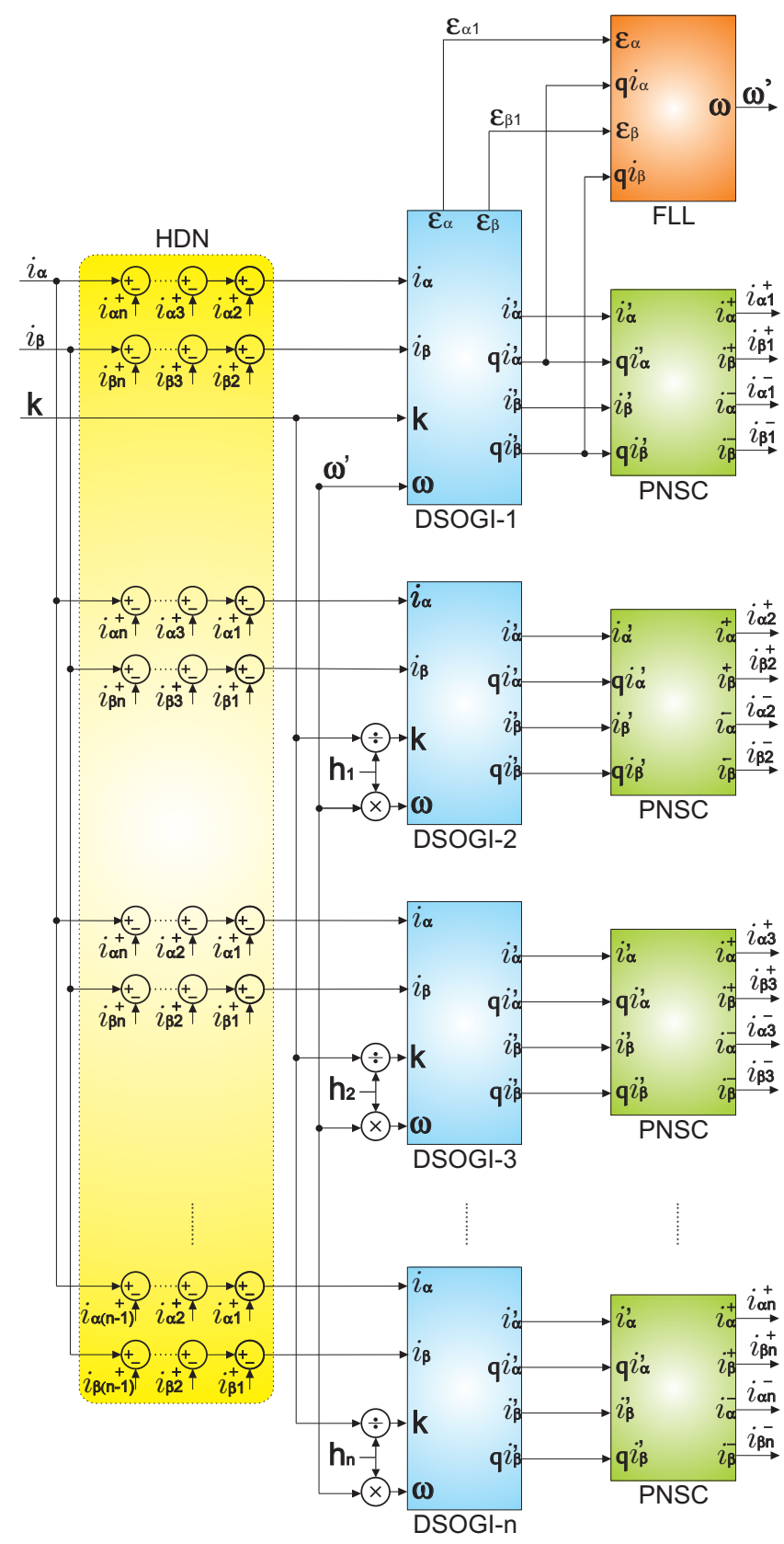

Fig. 9. Topology of a generic phase current reference generator for an active power filter.

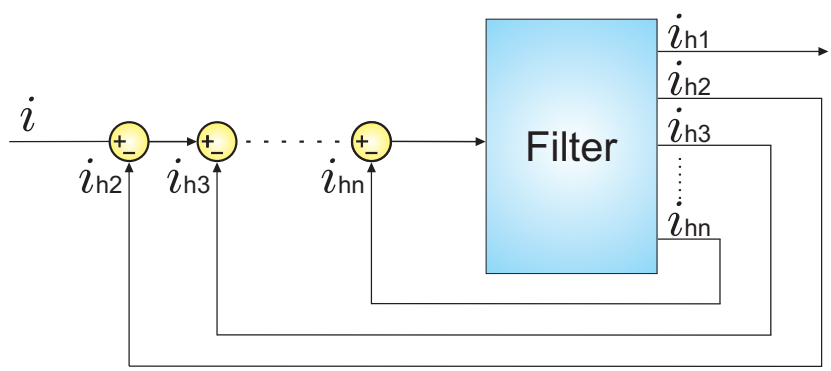

Fig. 10. Diagram of Harmonic Decoupling Network (HDN).

Therefore, the multi-channel resonant filter can be configured to filter a varied number of harmonics, simply by including or removing channels (HDN, DSOGI and PNSC). 

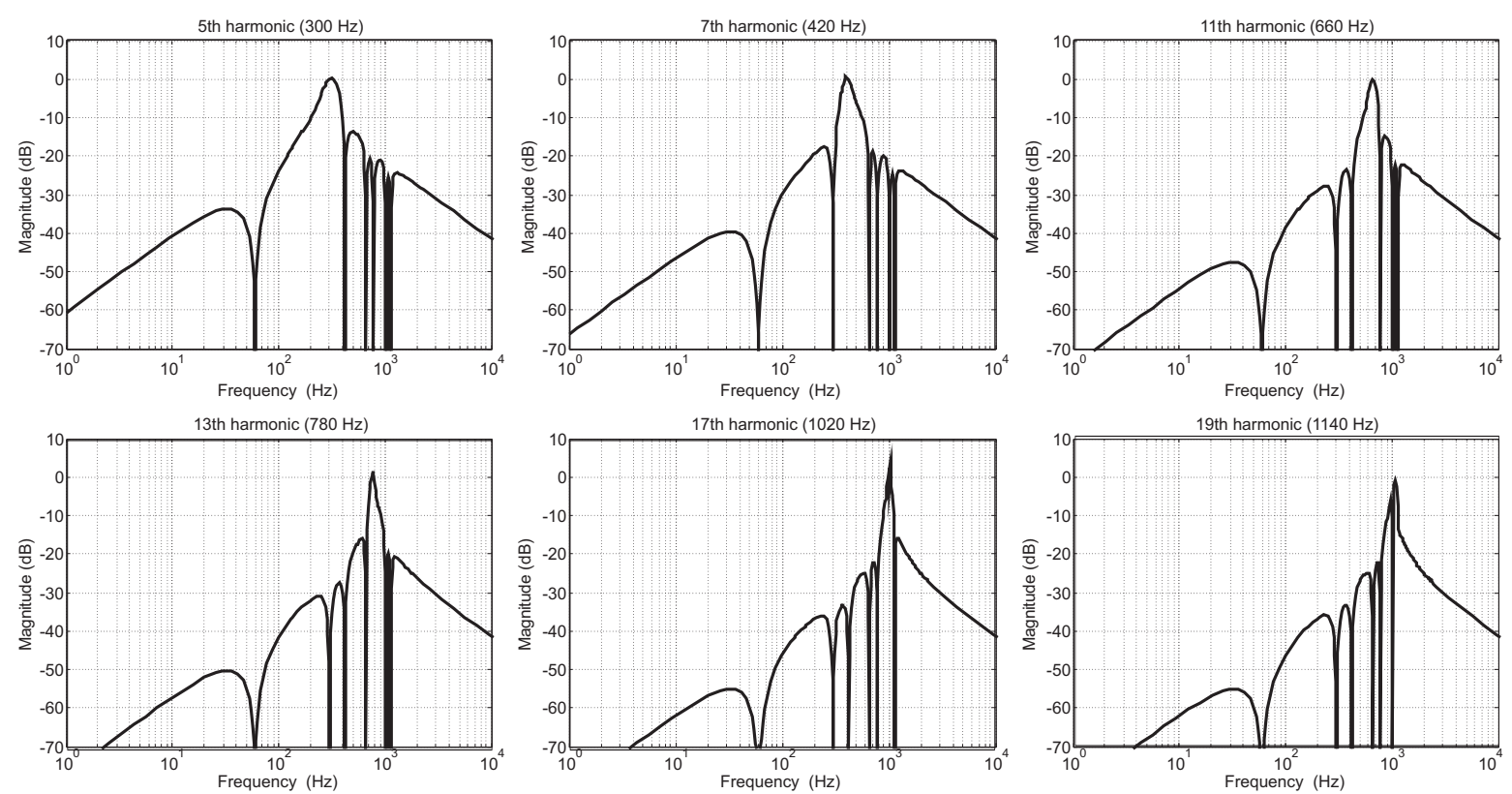

Fig. 11. Gain frequency response of the transfer function (11) for $5^{\text {th }}, 7^{\text {th }}, 11^{\text {th }}, 13^{\text {th }}, 17^{\text {th }}$ and $19^{\text {th }}$ harmonics.

\section{SIMULATION AND EXPERIMENTAL RESULTS}

The performance of this new reference current detection application using a multi-resonant filter and presented in this paper has been evaluated by simulation and experimentally in the laboratory. For a better understanding, this section is divided into three parts:

- Performance comparison between two algorithms, one based on MSOGI and the another on SRF.

- Comparison between simulation and experimental results.

- Simulation of selective compensation.

The simulations are performed in $\mathrm{S}$ domain (continuous).

The experiments are performed using the Texas Instrument's TMS320F28335 microcontroller clocked at $150 \mathrm{MHz}$ and floating-point hardware. A three-phase sinusoidal voltage generator is assembled from a voltage converter and a LC filter, to generate frequency changes and phase jumps on the load circuit. The charts of experimental results presented were generated from the current values read by the data acquisition boards and the values calculated internally in the DSP by the multi-resonant filter. The time required for selecting each harmonic component is 12.6 us, which corresponds to 1890 instruction cycles. With this parameter, the sampling frequency can be adjusted to improve the performance of the algorithm, which in this case was set at $20 \mathrm{kHz}$. The controllers were discretized using the Tustin method.

\section{A. Simulation - Comparison between MSOGI and SRF Application}

To examine the accuracy and stability of applications, a block diagram was developed to simulate the two generating reference currents methods. The first based on MOGI presented in this article and the second based on SRF developed in [8]. As shown in Figure 12, a three-phase current generator is implemented in order to simulate three types of grid disorders such as unbalanced phases, shift phases and frequencies change. The MSOGI-FLL and SRF-PLL block represent two methods of generating reference currents.

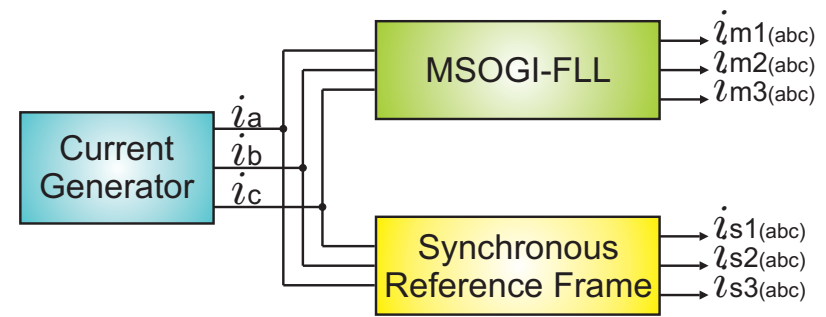

Fig. 12. Block diagram implemented in PSIM, in order to simulate and compare the harmonic components generated with harmonic component detected by MSOGI and SRF.

Regardless of the type of disorder presented by the generator, the current have several harmonic components, such as $10 \%$ of $5^{\text {th }}, 5 \%$ of $7^{\text {th }}, 2.5 \%$ of $11^{\text {th }}$ and $1.25 \%$ of $13^{\text {th }}$ harmonic. To facilitate the comparison between relevant methods only $7^{\text {th }}$ harmonic is analyzed.

First of all, $\alpha \beta$ components behavior is presented in Figure 13 , and shown three types of grid disorders such as unbalanced phases, shift phases and frequencies change.

As seen in the three graphs in Figure 14(a) the SRF method can not make the correct tracking phase when the existence of harmonic components. This phase error also causes the amplitude error in the harmonic detected. Figure 14(b) shows that current unbalanced do not interfere significantly in the responses of both algorithms. Figures 14(c) and 14(d) show that after the phase jump and frequency change both algorithms return to steady state after a fundamental frequency cycle, but SRF algorithm keeps the phase and amplitude error.

As seen in Figure 14, the application based on the MSOGI method estimates a $7^{\text {th }}$ harmonic near to the real, even after application of the disturbances. 

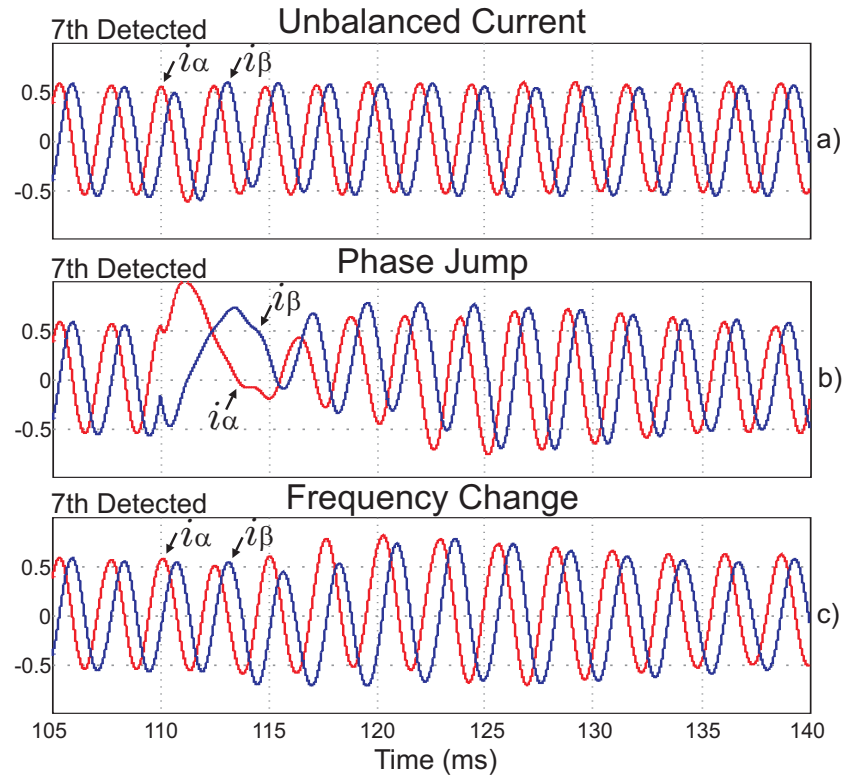

Fig. 13. $i_{\alpha \beta}$ components detected by MSOGI-FLL. At $110 \mathrm{~ms}$ a disorder is applied. (a) Unbalanced loads. (b) $+45^{\circ}$ phase jump. (c) Frequency change $(60 \mathrm{~Hz}->55 \mathrm{~Hz})$.

\section{B. Simulation/Experimental - Harmonic Components Detected in Disturbances Situations}

The simulations and experimental tests were performed based on the platform presented in Figure 15. To enable an accurate comparison between the two situations, the voltage used in the simulation was sampled during the course of the experimental test, so the control system input signals are the same. The voltage generator was implemented in order to produce various types of disturbances on the mains, such as frequency changes and phase jumps. The loads circuit shown enables the application to study three types of threephase loads; linear, non-linear and unbalanced load. The distortion of analyzed curent was generated using the same load circuit used for both. Variations in the currents were carried out triggering the switches $S w_{1}$ and $S w_{2}$, as required by the experiment.

The application developed in this work proposes the estimation of two harmonic components. This can be expanded to more components simply by adding new MSOGI structure in parallel to the existing ones, as seen in the section VII. The selection of the $5^{\text {th }}$ and $7^{\text {th }}$ harmonics is made on the load current. The $5^{\text {th }}$ harmonic is defined as a negative sequence, which uses the signal outputs available in $i_{\alpha}^{-}$and $i_{\beta}^{-}$ of the circuit shown in Figure 9, and $7^{\text {th }}$ harmonic is defined as a positive sequence, which uses in this case the outputs $i_{\alpha}^{+}$ and $i_{\beta}^{+}$for the same circuit.

In MSOGI-FLL simulations, the values used for $k$ and $\Gamma$ are respectively $\sqrt{2}$ and 50. Applying these values in (7) and (9), can be calculated $t_{s(S O G I)}=17.5 \mathrm{~ms}$ and $t_{s(F L L)}=100 \mathrm{~ms}$, according theory when $t_{s(F L L)} \geq 2 . t_{S(S O G I)}$. The value of $\gamma$ changes for each value of instantaneous current calculated by $I=\sqrt{i_{\alpha}^{2}+i_{\beta}^{2}}$ and applied in (9).

1) Non-linear loads: In order to describe the system behavior when connecting non-linear loads, the circuit shown
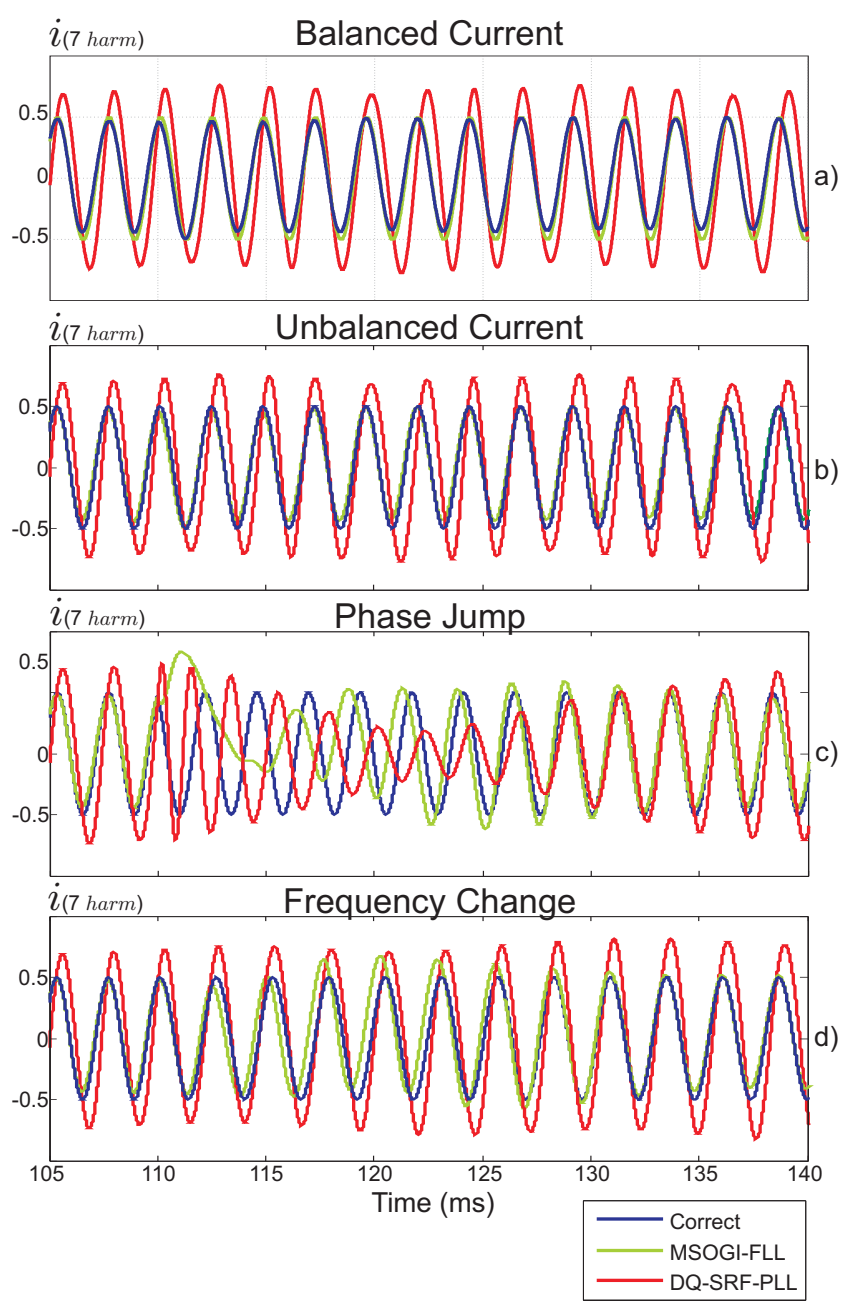

Fig. 14. Comparison between the $7^{\text {th }}$ harmonic generated and detected by methods SOGI and SRF. Pictures show a single phase current. At $110 \mathrm{~ms}$ a disorder is applied. (a) Balanced loads. (b) Unbalanced loads. (c) Phase jump $\left(+45^{\circ}\right)$. (d) Frequency change $(60$ $\mathrm{Hz}->55 \mathrm{~Hz})$.

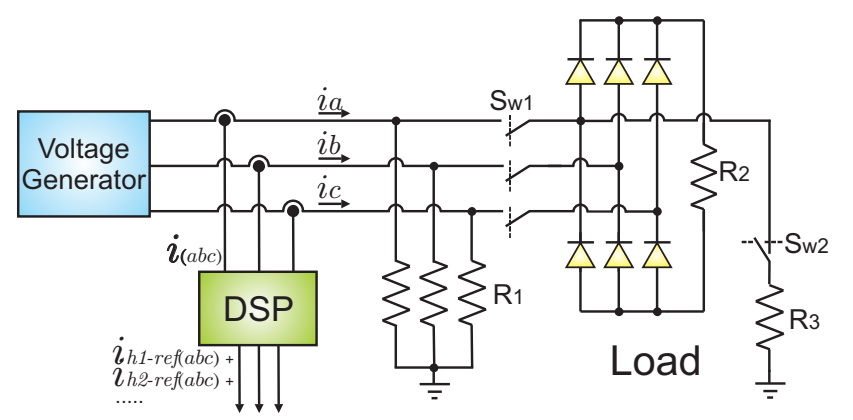

Fig. 15. Circuit used to simulate and experiment harmonic components detection with a linear, non-linear and unbalanced threephase load.

in Figure 15 is used with the values described on Table I. During system start up, switches $S w_{1}$ and $S w_{2}$ are open. After $100 \mathrm{~ms}$ of steady state, the $S w_{1}$ switch is closed, introducing a three-phase non-linear load onto the system. As seen in the graphs of Figures 16(c) and 16(d) following the introduction of a non-linear load to the circuit, the multi-resonant filter - in less than half a cycle of the fundamental frequency detected the $5^{\text {th }}$ and $7^{\text {th }}$ harmonics of the fundamental current. 
TABLE I

Circuit Parameters

\begin{tabular}{c|c}
\hline \hline Phase Voltage & $70.71 V_{R M S}$ \\
\hline Grid Frequency & $60 \mathrm{~Hz}$ \\
\hline R1 load & $15 \Omega$ \\
\hline R2 load & $50 \Omega$ \\
\hline R3 load & $15 \Omega$ \\
\hline
\end{tabular}
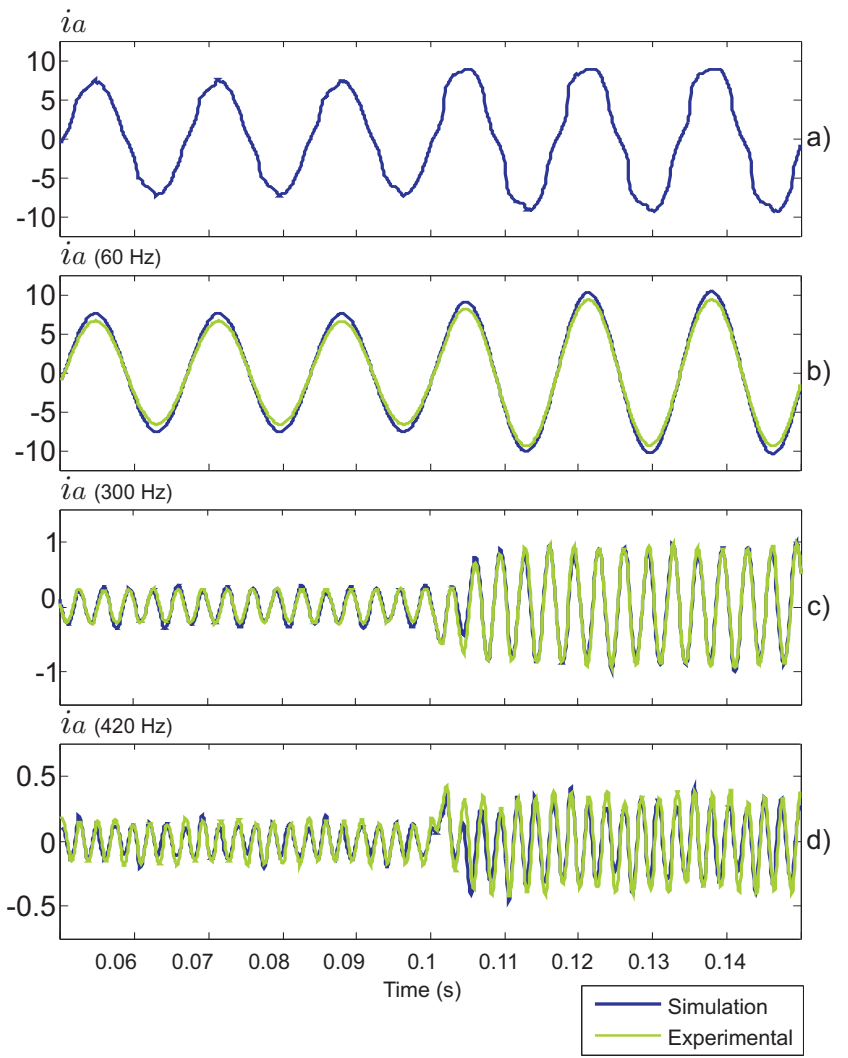

Fig. 16. Non-Linear loads. At $100 \mathrm{~ms}$ a nonlinear load is connected to the circuit. (a) Phase A current. (b) Fundamental current filtered. (c) $5^{\text {th }}$ harmonic filtered. (d) $7^{\text {th }}$ harmonic filtered.

In the experimental tests, a non-linear three-phase load is connected to the loads circuit by operating an electronic switch (MOSFET) Comparing the experimental results with the simulation results shown in Figure 16, a substantial similarity in noted between them. The current harmonics shown in the graphs of Figures 16(c) and 16(d) before the non-linear load connection to the circuit is a noise produced by the voltage generator. In the simulations, these currents also appear, since the simulations use the voltage values sampled in experimental tests.

2) Unbalanced loads: To obtain the response of the proposed method when subjected to unbalanced three-phase currents, once again the circuit of loads of Figure 15 is used with the values described on Table I to generate such currents. The system starts with switch $S w_{1}$ closed, generating harmonic currents due to the non-linear load connected, and $100 \mathrm{~ms}$ after the start of the simulation, switch $S w_{2}$ is closed, increasing the load on phase $\mathrm{A}$ and with a consequent phase unbalance. Figure 17(a) shows the current waveform $\left(i_{a b c}\right)$ immediately before and after the extra load connection in phase A. As the circuit load has the neutral grounded, the currents of phases $\mathrm{B}$ and $\mathrm{C} i_{b c}$ remain unchanged.

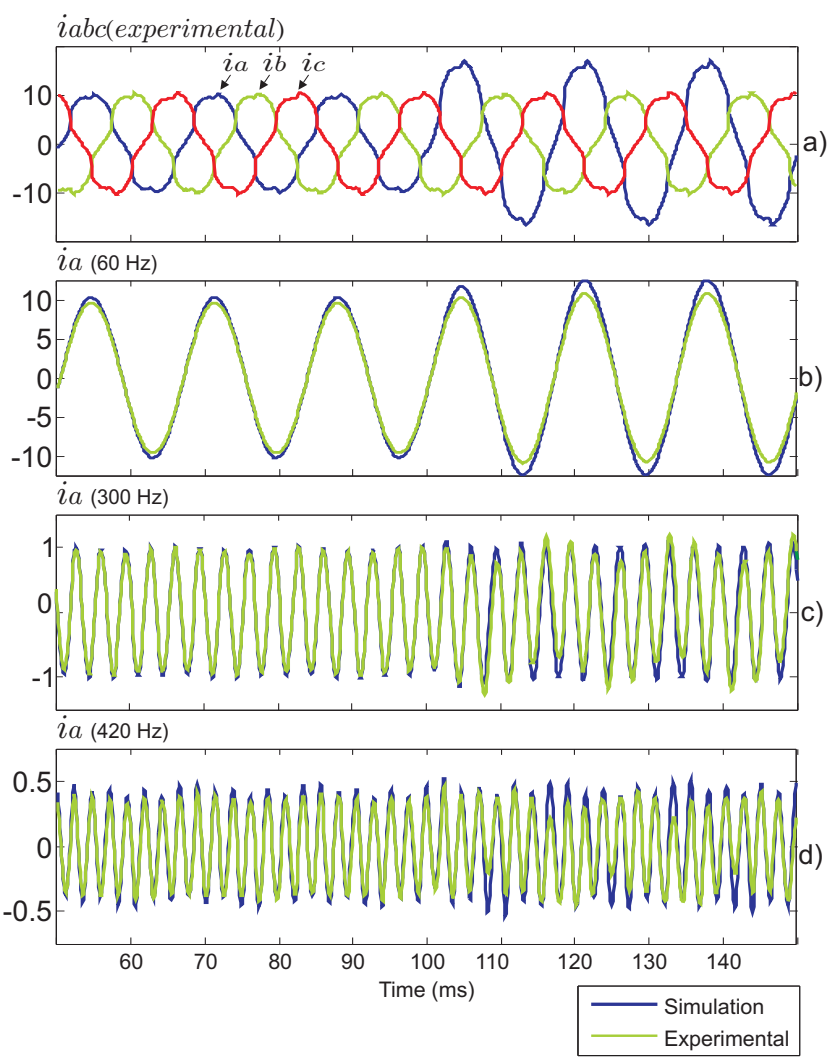

Fig. 17. Unbalanced loads. At $100 \mathrm{~ms}$ an extra load is connected at phase A. (a) Currents of phases A, B and C. (b) Fundamental current filtered at phase A. (c) $5^{\text {th }}$ harmonic filtered at phase A. (d) $7^{\text {th }}$ harmonic filtered at phase A.

At the experimental tests, a extra load is connected to the circuit by operating an electronic switch (TRIAC). Comparing the experimental results with the simulation results shown in Figure 17, a substantial similarity is noted between them. The MSOGI uses as input the symmetrical components $i_{\alpha}$ and $i_{\beta}$ of $i_{a b c}$. As $i_{\alpha}$ and $i_{\beta}$ values are calculated by combining the three phases, it is concluded that even if the phases are unbalanced, $i_{\alpha}$ and $i_{\beta}$ have an average amplitude of them.

3) Frequency change in power grid: The simulation begins with the load shown in Figure 15 with switches $S w_{1}$ closed and $S w_{2}$ open. In this way the system starts with a non-linear load. After $100 \mathrm{~ms}$ the voltage generator applies a frequency drop on the power grid, falling from $60 \mathrm{~Hz}$ to $55 \mathrm{~Hz}$. Thereby changing the frequency of the current. Since this method is composed of an adaptive filter in frequency (DSOGI-FLL), one notes in Figure 18(b) that in a little more than one cycle of the fundamental frequency, as designed, the system has stabilized, continuing to generate the reference harmonic corrections normally. The graphs of the experimental tests and the simulation is shown at the same figure, these are virtually identical.

4) Phase jump on power grid: Using the circuit shown in Figure 15, starting with the switches $S w_{1}$ closed and $S w_{2}$ open, the system starts with a nonlinear load. After $100 \mathrm{~ms}$, 

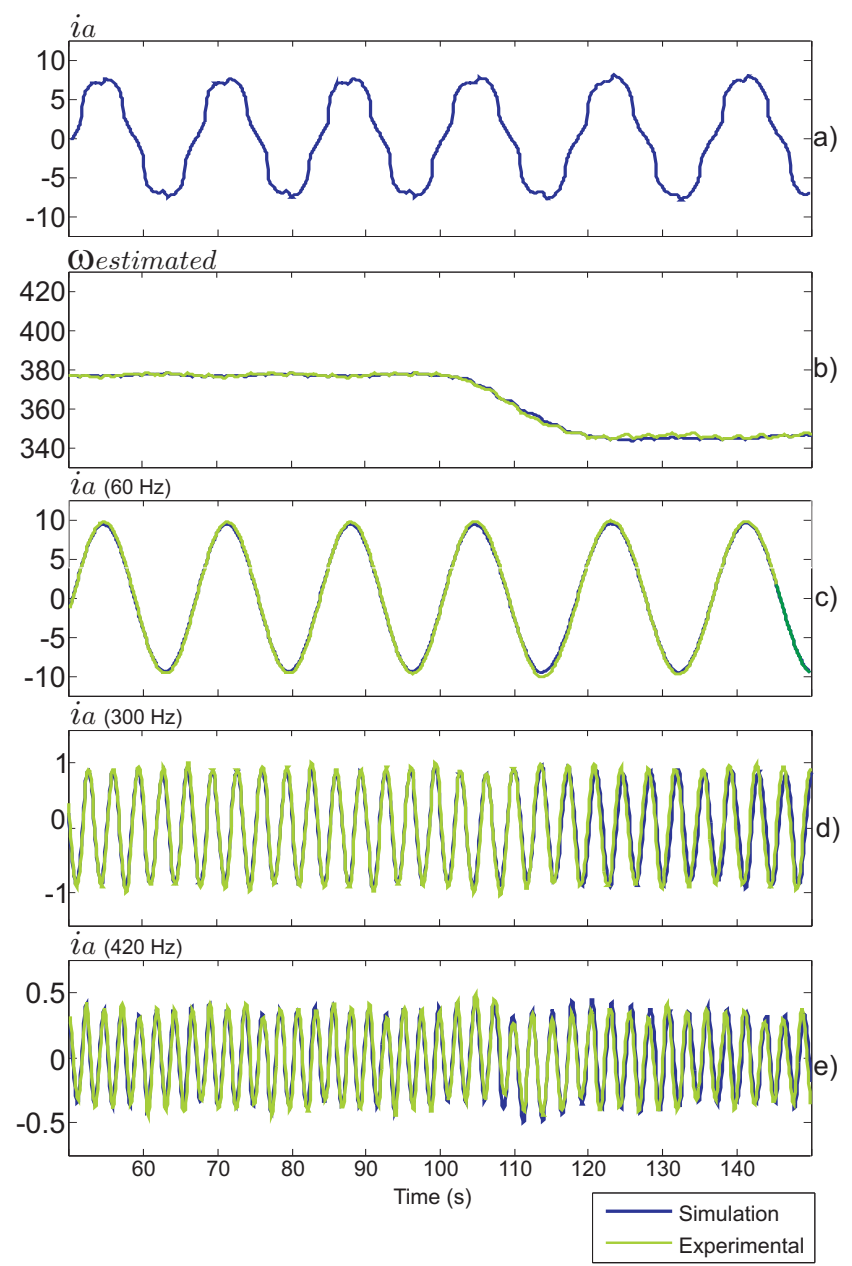

Fig. 18. Frequency Change. At $100 \mathrm{~ms}$ the grid frequency drops from $60 \mathrm{~Hz}$ to $55 \mathrm{~Hz}$. (a) Phase current during the frequency change. (b) $\omega$ detected by the MSOGI-FLL. (c) Fundamental current detected. (d) $5^{\text {th }}$ harmonic detected. (e) $7^{\text {th }}$ harmonic detected.

a phase jump is applied to the network voltage of $+45^{\circ}$. The adaptive filter DSOGI-FLL immediately increases the control frequency until the system reaches synchronism with the grid again. Noted in Figure 19 that in a little more than one cycle of the fundamental frequency, as designed, the system stabilizes and continues to generate the reference harmonic corrections normally.

Also using the load shown in Figure 15 starting with Sw1 contact closed and Sw2 contact open, will leave the system with a non-linear load. After $100 \mathrm{~ms}$, a $+45^{\circ}$ phase jump is applied to a power grid, hence the jump is followed by the current in the circuit. The adaptive filter DSOGI-FLL immediately increases the frequency control until the system becomes synchronized with the grid again. As seen in Figure 19 in a little more than one cycle of the fundamental frequency, as designed, the system stabilizes and continues to generate the harmonic reference normally.

The MSOGI-FLL increases or decreases its internal frequency until it becomes synchronized again with the power grid. Compared to the simulation shown in the same figure, these are virtually identical.

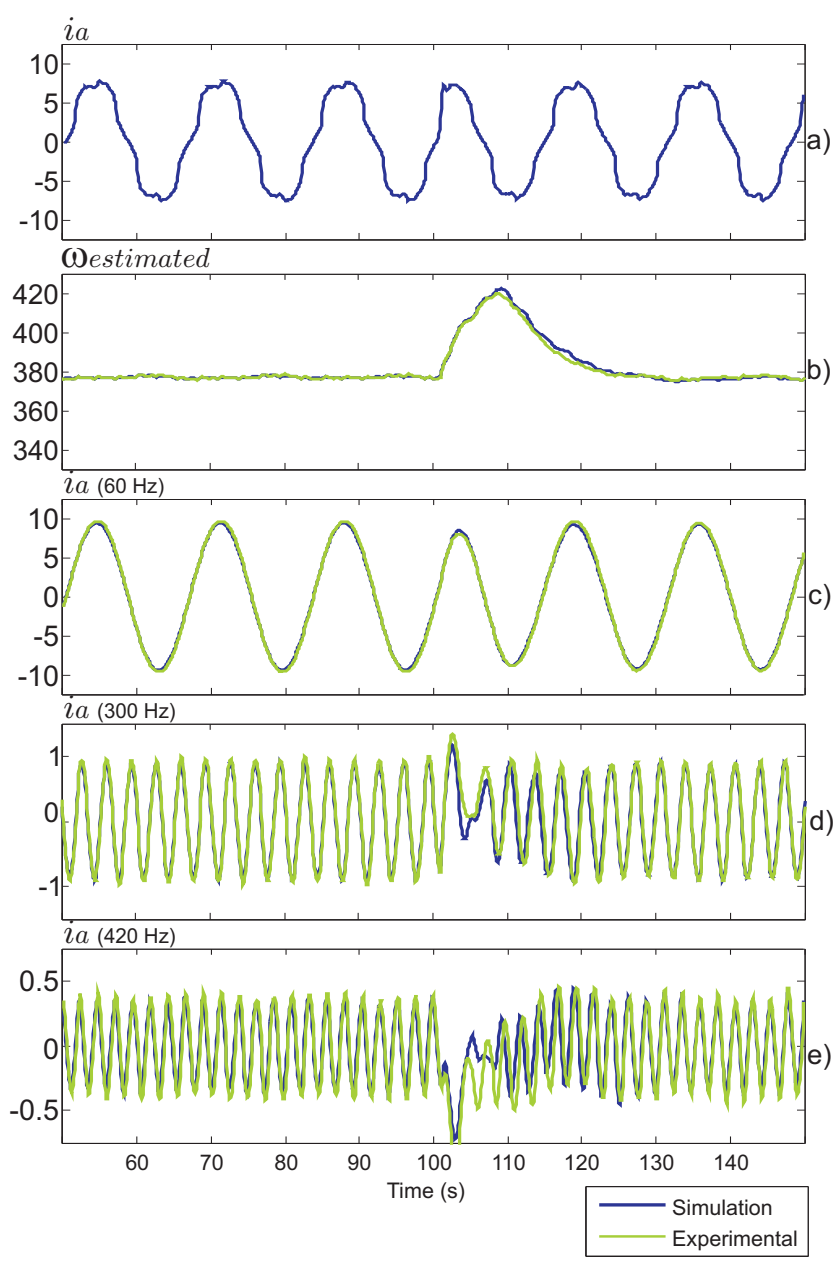

Fig. 19. Phase Jump. At $100 \mathrm{~ms}$ the power grid performs a $+45^{\circ}$ phase jump. (a) Phase current during the phase jump. (b) FLL detects the change in the phase and increases/decreases the control frequency to achieve the correct phase. (c) Fundamental current detected. (d) $5^{\text {th }}$ harmonic detected. (e) $7^{\text {th }}$ harmonic detected.

\section{Selective Harmonics Compensation}

In order to verify the harmonic attenuation of the selected components, the block diagram is shown in Figure 20, and the simulation was performed. For this simulation to be as close to reality as possible, the voltage values $\left(V_{a b c}\right)$ used in the simulation were sampled in the experimental test that was presented in the last section.

A three-phase system is represented by a sinusoidal stationary components [33], then a proportional resonant controller $\left(C_{P+R E S}\right)$ is used in place of proportional integral controller $\left(C_{P I}\right)$, since $C_{P I}$ leads to an oscillatory error which is not eliminated in steady state when the input is a sinusoidal signal. $C_{P+R E S}$ transfer function is given by (12) [34], [35].

$$
C_{(P+R E S)}=k_{p}+\sum_{h=1}^{n} \frac{k_{s h} \cdot s}{s^{2}+\left(h \cdot \omega_{0}\right)^{2}}
$$

1) Resistive load: Figure 21(a) shows the harmonic distribution of the current $\left(i_{a, b, c}\right)$ in a three-phase load, meaning switch $S w 1$ is open in Figure 20. The high quantity of harmonic components in Figure 21(a) is mainly due to nonlinearity of the charge, but also the voltages applied onto the 


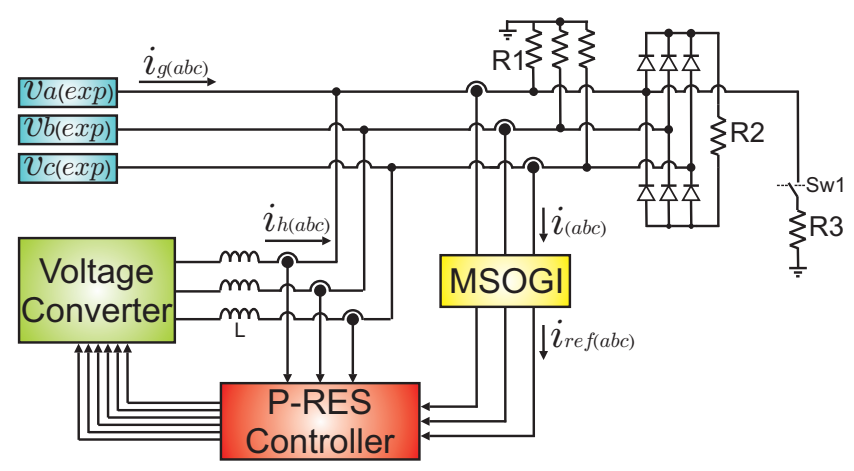

Fig. 20. Circuit used to simulate and experiment selective harmonics compensation with a linear, non-linear and unbalanced three-phase load.

circuit are extracted from real experimental tests. Figure 21(b) shows the current supplied by the voltage source $\left(i_{g(a b c)}\right)$, with attenuation of harmonic components compensated, as the selected harmonic components $\left(i_{h(a b c)}\right)$ were almost in their entirety provided by the voltage converter. Although in previous simulations the references of harmonic components were estimated to be very close to the actual harmonic components, especially in stable situations, the compensation was not performed in its entirety. This result can be improved with the use of multilevel topology voltage converters, and also using a Linear Power Amplifier.

The harmonic compensation in unbalanced loads is simulated with switch $S w 1$ closed in Figure 20. Figure 21 (c) presents the harmonic components on the load. By increasing the current on phase A due to input of a new linear load onto this phase, the value of the harmonic component of the current on this phase is kept constant, but the percentage of harmonic components in the graph in this phase decreased since the total current phase increases. The result shown in Figure 21 (d) behaved as the simulation with balanced loads.

Figure 21(a) shows the harmonic distribution of load current before and Figure 21(b) shows after selective compensation of $5^{\text {th }}$ and $7^{\text {th }}$ harmonics, which shows the high precision of the method. One observes that after the selective compensation, the amplitudes of the $5^{\text {th }}$ and $7^{\text {th }}$ harmonics dropped respectively from $10.8 \%$ to $1 \%$ and from $5.4 \%$ to $0.4 \%$.

Figure 21 shows that even with an unbalanced load, the system responded satisfactorily. The different levels of current on the phases did not stop the multi-resonant filter from detecting and filtering the preselected harmonic currents.

2) Inductive/Capacitive loads: In order to verify the behavior of MSOGI-FLL algorithm with inductive loads, simulation was performed using the circuit described in Figure 15. Switch $S w 1$ remains closed and $S w 2$ remains open. In series of $\mathrm{R} 1$ resistance, it was included an inductance of $100 \mathrm{mH}$. No abnormalitie situations are applied in the voltage converter. Figure 22(a) shows the current of circuit, and Figures 22(b) and 22(c) the harmonic distortion graph before and after the harmonic compensation respectively. This simulation shows that even with an inductive load, the system responded satisfactorily. The system works the same with capacitive loads. Inductive and capacitive loads produce
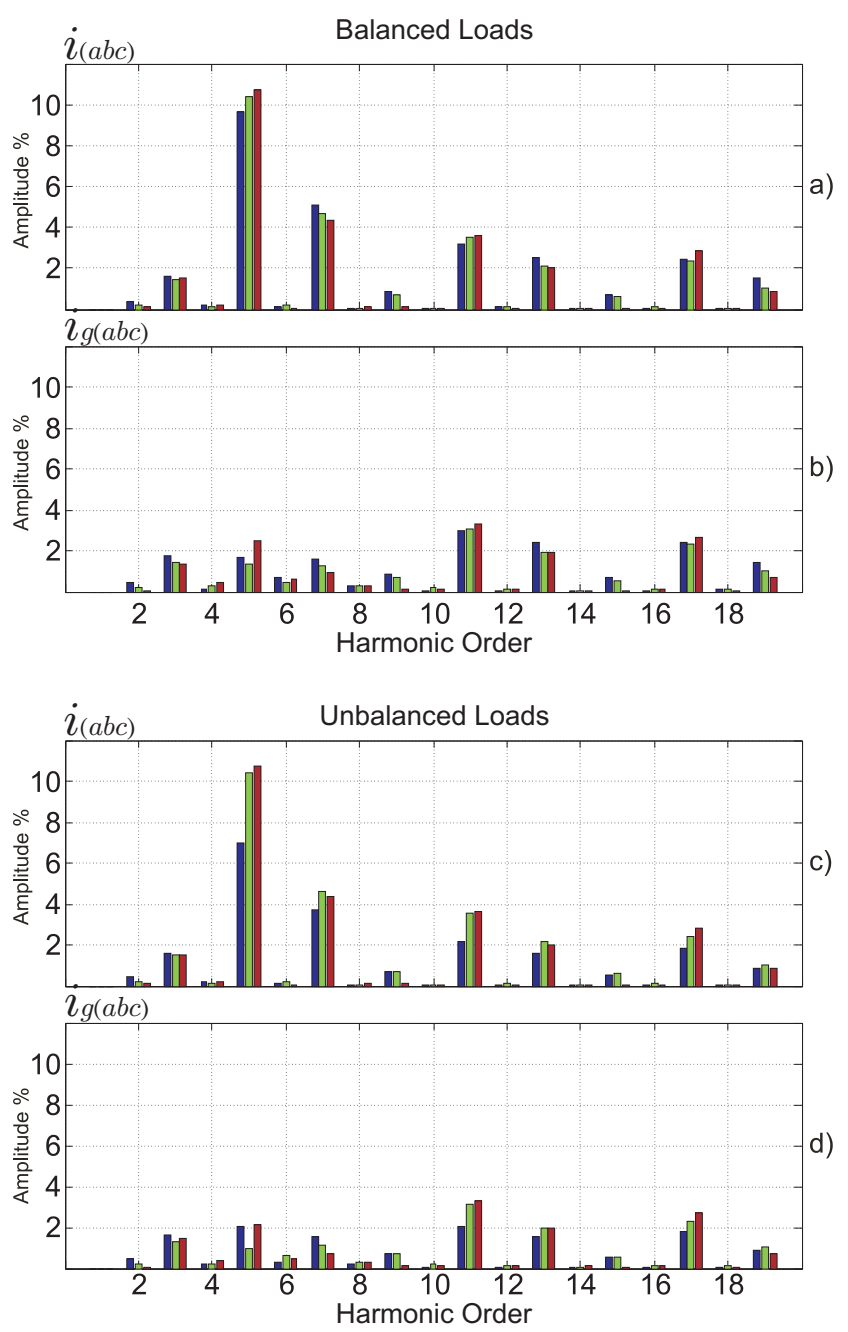

Fig. 21. Harmonic distortion graph. (a) Balanced load. Before the harmonic compensation. (b) Balanced load. After the $5^{\text {th }}$ and $7^{\text {th }}$ harmonic compensation. (c) Unbalanced load. Before the harmonic compensation. (d) Unbalanced load. After the $5^{t} h$ and $7^{t} h$ harmonic compensation.

different phases between the voltage and current. However, as the synchronization (detection of the frequency and the phase of the fundamental component) is performed on the current signal, the algorithm detects the current component harmonics independent of it being leading or lagging the grid voltage. However, further studies need to be performed on the transitory current of these loads.

\section{CONCLUSION}

This paper presented a new application for generating reference currents used in the selective compensation of threephase harmonic currents, based on the MSOGI-FLL method. The presented application does not use any trigonometric function, and these characteristics enable the use of little computational effort, allowing the microcontroller to operate in a high frequency sampling/switching. It is effective even when the system has unbalanced loads and fluctuations on the mains frequency. At steady state, the algorithm performance is not affected by inductive and capacitive loads. Simulations and experimental tests are presented in this article in order to validate this new application. In order to demonstrate 

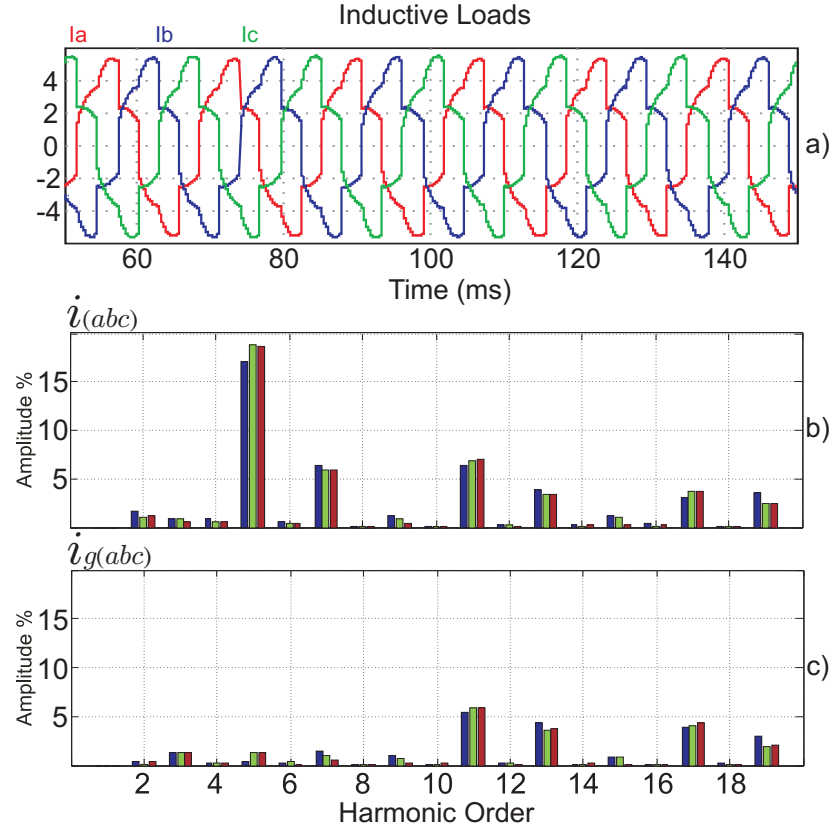

Fig. 22. Inductive load. (a) 3 phase current before compensation. (b) Before the $5^{\text {th }}$ and $7^{\text {th }}$ harmonic compensation. (c) After the $5^{\text {th }}$ and $7^{\text {th }}$ harmonic compensation.

the stability and speed of the control system response, phase jumps $\left(\right.$ shift $+45^{\circ}$ ) and frequency changes (drop of $5 \mathrm{~Hz}$ ) were applied. As expected, the graphs resulting from simulations and experiments are similar, since the loads used in both cases are equal. After the stabilization time of the proposed method, the harmonic component current detected is very close to the real component. The phase jumps and frequency changes applied in this paper were much greater than those that normally occur on the power grid, this consideration indicates that on the grid instability, settling time can be much smaller than presented here. The main contribution compared to previous works is to employ MSOGI-FLL to estimate harmonic components, and so far this method was used only for synchronizing voltage converters with three-phase systems in abnormalities situations.

\section{ACKNOWLEDGMENT}

This work was supported by the Higher Education Personnel Improvement Coordination (CAPES) - Brazilian Ministry of Education, the School of Electrical Engineering, Universidade Federal de Uberlândia (FEELT-UFU), and Instituto Federal de Goiás (IFG).

\section{REFERENCES}

[1] S. Karvekar, D. Patil, "Comparison of reference current generation for shunt active power filter using Goertzel Algorithm and Enhanced PLL", in International Conference on Circuits, Power and Computing Technologies (ICCPCT), pp. 620-625, 2014.

[2] R. L. de Araujo Ribeiro, R. M. Sousa, T. O. A. Rocha, C. C. Azevedo, "Enhanced Power Quality Compensation of Shunt Active Power Filters without Harmonic Detection Schemes", Brazilian Journal of
Power Electronics, vol. 19, no. 4, pp. 332-342, Nov 2014.

[3] G. J. Franca, B. J. C. Filho, "Series-Shunt Compensation for Harmonic Mitigation and Dynamic Power Factor Correction", Brazilian Journal of Power Electronics, vol. 17, no. 3, pp. 641-650, Aug 2012.

[4] H. K. M. Paredes, D. I. Brandao, E. V. Liberado, F. P. Marafao, "Compensacao Ativa Paralela baseada na Teoria de Petencia Conservativa", Brazilian Journal of Power Electronics, vol. 17, no. 1, pp. 409-418, Feb 2012.

[5] L. F. C. Monteiro, J. L. Afonso, J. G. Pinto, E. H. Watanabe, M. Aredes, H. Akagi, "Compensation Algorithms based on the P-Q and CPC Theories for Switching Compensators in Micro-Grids", Brazilian Journal of Power Electronics, vol. 14, no. 4, pp. 259268, Dec 2009.

[6] M. C. Cavalcanti, G. M. de Souza Azevedo, B. de Aguiar Amaral, F. de Assis dos Santos Neves, D. C. M. K. C. de Oliveira, "A Grid Connected Photovoltaic Generation System with Compensation of Current Harmonics and Voltage Sags", Brazilian Journal of Power Electronics, vol. 11, no. 2, pp. 93101, Jul 2006.

[7] J. A. Pomilio, S. M. Deckmann, "Caracterizacao e Compensacao de Harmonicos e Reativos de Cargas Nao-Lineares Residenciais e Comerciais", Brazilian Journal of Power Electronics, vol. 11, no. 1, pp. 9-16, Mar 2006.

[8] M. P., "A closed-loop selective harmonic compensation for active filters", IEEE Transactions on Industry Applications, vol. 37, no. 1, pp. 81-89, Jan 2001.

[9] A. L., H. S., L. C., F. Blaabjerg, "Selective harmonic current mitigation with shunt active power filter", in European Conference on Power Electronics and Applications, pp. 1-10, 2007.

[10] L. Asiminoaei, S. Kalaschnikow, S. Hansen, "Overall and selective compensation of harmonic currents in Active Filter applications", in Compatibility and Power Electronics, pp. 153-160, 2009.

[11] H. Zhou, Y. W. Li, N. Zargari, Z. Cheng, R. Ni, Y. Zhang, "Selective Harmonic Compensation (SHC) PWM for Grid-Interfacing High-Power Converters", IEEE Transactions on Power Electronics, vol. 29, no. 3, pp. 1118-1127, March 2014.

[12] W. Hao, Z. Chao, Y. Geng, D. Ji-hong, "Detecting and close-loop control methods for selective-harmoniccompensation active power filter", in International Power Electronics and Motion Control Conference (IPEMC), pp. 206-209, 2004.

[13] O. M. Solomon, "The use of DFT windows in signal-to-noise ratio and harmonic distortion computations", IEEE Transactions on Instrumentation and Measurement, vol. 43, no. 2, pp. 194-199, Apr 1994.

[14] F. Zhang, Z. Geng, W. Yuan, "The algorithm of interpolating windowed FFT for harmonic analysis of electric power system", IEEE Transactions on Power Delivery, vol. 16, no. 2, pp. 160-164, Apr 2001. 
[15] J. Rosendo Macias, A. Exposito, "Efficient movingwindow DFT algorithms", IEEE Transactions on Circuits and Systems II: Analog and Digital Signal Processing, vol. 45, no. 2, pp. 256-260, Feb 1998.

[16] L. Asiminoaei, F. Blaabjerg, S. Hansen, "Detection is key - Harmonic detection methods for active power filter applications", IEEE Industry Applications Magazine, vol. 13, no. 4, pp. 22-33, July 2007.

[17] S. Bhattacharya, T. M. Frank, D. Divan, B. Banerjee, "Active filter system implementation", IEEE Industry Applications Magazine, vol. 4, no. 5, pp. 47-63, Sep 1998.

[18] H. Kim, H. Akagi, "The instantaneous power theory based on mapping matrices in three-phase four-wire systems", in Power Conversion Conference, pp. 361366, 1997.

[19] M. Newman, D. Zmood, D. Holmes, "Stationary frame harmonic reference generation for active filter systems", IEEE Transactions on Industry Applications, vol. 38, no. 6, pp. 1591-1599, Nov 2002.

[20] C. Xie, C. He, H. Yan, G. Chen, H. Yang, "Digital Generalized Integrators of current control for threephase Active Power filter with selective harmonic compensation", in Applied Power Electronics Conference and Exposition (APEC), pp. 748-753, 2012.

[21] P. Rodriguez, A. Luna, I. Candela, R. Teodorescu, F. Blaabjerg, "Grid synchronization of power converters using multiple second order generalized integrators", in Annual Conference of IEEE Industrial Electronics (IECON), pp. 755-760, 2008.

[22] P. Rodriguez, A. Luna, I. Candela, R. Mujal, R. Teodorescu, F. Blaabjerg, "Multiresonant Frequency-Locked Loop for Grid Synchronization of Power Converters Under Distorted Grid Conditions", IEEE Transactions on Industrial Electronics, vol. 58, no. 1, pp. 127-138, Jan 2011.

[23] P. Rodriguez, A. Luna, R. Munoz-Aguilar, I. Etxeberria-Otadui, R. Teodorescu, F. Blaabjerg, "A Stationary Reference Frame Grid Synchronization System for Three-Phase Grid-Connected Power Converters Under Adverse Grid Conditions", IEEE Transactions on Power Electronics, vol. 27, no. 1, pp. 99-112, Jan 2012.

[24] P. Rodriguez, A. Luna, M. Ciobotaru, R. Teodorescu, F. Blaabjerg, "Advanced Grid Synchronization System for Power Converters under Unbalanced and Distorted Operating Conditions", in Annual Conference of IEEE Industrial Electronics (IECON), pp. 5173-5178, 2006.

[25] W. Lyon, Application of the Method of Symmetrical Components, McGraw-Hill, 1937.

[26] P. Rodriguez, R. Teodorescu, I. Candela, A. Timbus, M. Liserre, F. Blaabjerg, "New Positive-sequence Voltage Detector for Grid Synchronization of Power Converters under Faulty Grid Conditions", in Power Electronics Specialists Conference (PESC), pp. 1-7, 2006.

[27] M. Mojiri, A. Bakhshai, "An adaptive notch filter for frequency estimation of a periodic signal", IEEE
Transactions on Automatic Control, vol. 49, no. 2, pp. 314-318, Feb 2004.

[28] M. Mojiri, M. Karimi-Ghartemani, A. Bakhshai, "Estimation of Power System Frequency Using an Adaptive Notch Filter", IEEE Transactions on Instrumentation and Measurement, vol. 56, no. 6, pp. 2470-2477, Dec 2007.

[29] M. Ciobotaru, R. Teodorescu, F. Blaabjerg, "A New Single-Phase PLL Structure Based on Second Order Generalized Integrator", in Power Electronics Specialists Conference (PESC), pp. 1-6, 2006.

[30] F. G.F., P. J.D., E.-N. A., A Feedback Control of Dynamic Systems, Prentice Hall, 2002.

[31] R. Teodorescu, M. Liserre, P. Rodriguez, Grid Converters for Photovoltaic and Wind Power Systems, "John Wiley and Sons, Ltd.", 2011.

[32] C. L. Fortescue, "Method of Symmetrical CoOrdinates Applied to the Solution of Polyphase Networks", Transactions of the American Institute of Electrical Engineers, vol. XXXVII, no. 2, pp. 10271140, July 1918.

[33] E. Clarke, "Circuit Analysis of AC Power Sistems", John Wiley and Sons, Inc, vol. 1, 1950.

[34] S. Fukuda, T. Yoda, "A novel current tracking method for active filters based on a sinusoidal internal model", in Industry Applications Conference, vol. 4, pp. 21082114, 2000.

[35] R. Teodorescu, F. Blaabjerg, Proportional-Resonant Controllers. A New Breed of Controllers Suitable for Grid-Connected Voltage-Source Converters, vol. 3, CD-ROM, pp. 9-14, 2004.

\section{BIOGRAPHIES}

Cássio Xavier Rocha, he graduated in Electrical Engineering from Universidade Federal de Uberlândia in 1991. Completed the master's degree in Electrical Engineering at the same university in 1998, at the moment he is pursuing his doctoral degree and is currently a lecturer at the Federal Institute of Education, Science and Technology of Goiás.

José Roberto Camacho, was born in Taquaritinga, São Paulo State, Brazil. in 1954, his BSc degree in Electrical Engineering was obtained at UFU in 1978, and his MSc degree in Electrical Engineering at Universidade Federal de Santa Catarina in 1987, earned his $\mathrm{PhD}$ in Electrical Engineering at the University of Canterbury, New Zealand, in 1993. He is currently a Professor at UFU - Universidade Federal de Uberlândia, Minas Gerais, Brazil.

Ernane Antônio Alves Coelho, he graduated in Electrical Engineering from Universidade Federal de Minas Gerais (1987), MSc degree in Electrical Engineering from Universidade Federal de Santa Catarina (1989) and doctoral degree in Electrical Engineering from Universidade Federal de Minas Gerais (2000). He is currently Associate Professor 2 of the Universidade Federal de Uberlândia.

Wanderley Alves Parreira, graduated in Electrical Engineering from Universidade Federal de Minas Gerais in 1974, and MSc degree in Electronic Industrial Engineering by UFMG (1985) with a doctoral degree in Power Electronics by UFU (2014). Since 2004 he is Professor at CEFET-MG. 